\title{
Modulatory Effect of Decalepis hamiltonii on Ethanol- Induced Neurotoxicity in Drosophila melanogaster
}

\author{
Samaneh Reiszadeh Jahromi ${ }^{*}$ \\ 'Department of Biology, University of Sistan and Baluchestan, Zahedan, Iran
}

*Correspondence to Samaneh Reiszadeh Jahromi,

Received January 10, 2018 Accepted February 10, 2018 Published online June 30, 2018

\begin{abstract}
Introduction: T Drosophila melanogaster is a suitable in vivo model organism to study the neurotoxic effects of ethanol. In the present study, the behavioral responses, levels of oxidative markers, and activity of antioxidant enzymes were investigated in ethanol-exposed Drosophila flies.

Methods: Adult flies were exposed to absolute ethanol using ethanol exposure chamber. Then, their resistance against ethanol vapor was measured by monitoring their locomotion. Biochemical assays were applied to quantify antioxidant enzymes activity in the brains of ethanol exposed flies.

Results: The results showed that acute ethanol exposure led to the hyperactivity of flies. If alcohol exposure was prolonged, then sedation could occur in the experimental flies. The levels of reactive oxygen species (ROS) and lipid peroxidation (LPO) as cellular markers of oxidative stress considerably increased in ethanol-exposed flies while glutathione (GSH) level declined. Higher activities of catalase (CAT) and superoxide dismutase (SOD) were observed in the ethanol-exposed flies. Ethanol neurotoxicity became more evident when a remarkable decrease in acetylcholine esterase (AChE) activity was seen in the ethanol-exposed flies. Treatment with Decalepis hamiltonii aqueous extract increased the time of ST50 and decreased the RC50 values of ethanol-exposed flies. Moreover, we demonstrated that $D$. hamiltonii pre-treatment diminished ROS and LPO levels in the ethanol-exposed flies. D. hamiltonii treatment resulted in augmentation of GSH level and activity of CAT and SOD enzymes.

Conclusion: This is the first report on the protective effects of $D$. hamiltonii natural antioxidants in D. melanogaster on oxidative stress induced by ethanol.

Keywords: Drosophila melanogaster, Decalepis hamiltonii, Ethanol, ST50, RC50, Oxidative stress
\end{abstract}

\section{Introduction}

The use of Drosophila melanogaster as an in vivo model to learn the role of oxidative stress in neuronal dysfunction is beneficial over the other animal models for several reasons. From evolutionary point of view, there is a high level of homology and conservation between human genome and fly genome. Moreover, fruit fly possesses several signal transduction pathways homologous to that of human being, which makes this insect a suitable model. The fly central nervous system (CNS) has much smaller quantity of cells and interestingly works in the same manner as it in mammalian systems.

Excessive consumption of ethanol is associated with degrees of dementia, liver injury, compromised immunity, hypertension, enhanced cancer risk, and neurobehavioral harms. In utero exposure to alcohol may lead to smaller brain size and lifelong neurobehavioral disturbances, which are commonly referred to as fetal alcohol syndrome (FAS). ${ }^{1}$ High alcohol concentration grounds immediate destruction via solubilizing cell membranes and radically changing tertiary structure of proteins. ${ }^{2}$ At lower concentrations, regulated forms of cell demise can occur. The mediators considered imperative for ethanol-induced cytotoxicity comprise both oxidative and non-oxidative metabolites. Extreme ethanol consumption persuades oxidative stress and causes brain damage. Neurotoxicity of ethanol is associated with augmentation in generation of reactive oxygen species (ROS) and decline in endogenous antioxidant defenses. ${ }^{3}$

ROS are molecular entities that have reactions with cellular components leading

(C) 2018 The Author(s); Published by Zabol University of Medical Sciences. This is an open-access article distributed under the terms of the Creative Commons Attribution License (http://creativecommons.org/licenses/by/4.0), which permits unrestricted use, distribution, and reproduction in any medium, provided the original work is properly cited. 
to detrimental effects on cellular functions. The major parts of cellular ROS are produced during incomplete reduction of oxygen to water. ${ }^{4}$ In aerobic organisms, the energy needed for biological functions is produced in the form of ATP via electron transport chain (ETC). Therefore, mitochondrial functional compromise has major effects on oxidative homeostasis. ${ }^{5}$ Decreased activity of complex I of mitochondrial ETC has been observed in Parkinson disease (PD) patients, cybrid cell lines, and platelets. ${ }^{6}$ This inhibition may result in the production of ROS which when generated in the vicinity, could affect the respiratory chain resulting in further inhibition by subsequent ROS generation and finally mitochondrial damage. ${ }^{7}$

Antioxidants play a major role in scavenging ROS, removal of free radicals, and inhibition of ROS generation. They are classified into two main groups: enzymatic and nonenzymatic. Enzymatic antioxidants consist of a number of proteins including superoxide dismutase (SOD), catalase (CAT) as well as glutathione (GSH) peroxidase along with some supporting enzymes. Nonenzymatic antioxidants are classified into two groups: directly acting and indirectly acting antioxidants. Directly acting antioxidants are really essential in defense against ROS. Most of them are lipoic acid and ascorbic acid, carotenoids and polyphenols which are derived from dietary sources. The cell itself produces some of these antioxidants. The second group mostly comprises chelating agents that bind to redox metals to prevent the generation of free radicals. ${ }^{8} \mathrm{GSH}$, the major thiolcontaining antioxidant with low molecular weight is made from cysteine, glutamate, and glycine.

Decalepis hamiltonii is a monotypic climbing shrub with aromatic tuberous roots that belongs to the Asclepiadaceae family and grows in scrub forest of the southern part of peninsular India. Its tuberous roots are being used in the ancient Indian Ayurveda as an appetizer, for flatulence relief, and as a general tonic. Its roots are also used as general vitaliser and blood purifier in folk medicine. ${ }^{9}$ It has been shown that $D$. hamiltonii roots have antimicrobial, antifungal, antidiabetic, antioxidant, cytoprotective, chemoprotective, and neuroprotective activities. ${ }^{10}$ In this connection, the edible roots of $D$. hamiltonii were selected for the present study because they have strong antioxidant potential. It is worth to note that a number of novel antioxidant compounds have been isolated and characterized from the aqueous extract of $D$. hamiltonii roots. ${ }^{9}, 11$

Earlier studies have revealed the antioxidant and neuroprotective potential of $D$. hamiltonii root extract in the albino rat. ${ }^{12,13}$ The neuroprotective effect of $D$. hamiltonii has been shown by in vivo and in vitro studies in rats. ${ }^{13}$ To provide evidence for the involvement of oxidative stress in ethanol-induced behavioral impairments, the neuromodulatory action of antioxidant molecules of aqueous extract of $D$. hamiltonii on antioxidant defense system of wild-type Drosophila was evaluated. We investigated the sedation time and recovery time as neurofunctional parameters to explore ethanolmediated locomotory dysfunction in flies.

\section{Materials and Methods}

Fly Stocks

The Drosophila stocks used in the present study were fed on standard wheat cream agar medium supplemented with dry yeast granules at $22 \pm 1^{\circ} \mathrm{C}, 70 \%-80 \%$ relative humidity, and $12 \mathrm{~h}$ light/12 $\mathrm{h}$ dark cycle in a vivarium.

\section{Negative Geotaxis Assay}

The locomotory function of the flies was determined by negative geotaxis assay as described by Feany and Bender. ${ }^{14}$ Thirty adult male flies were placed in a graduated plastic tube ( $25 \mathrm{~cm}$ length, $2 \mathrm{~cm}$ diameter). After a 10 -minute rest period, the experimental flies were gently tapped down to the bottom of the tube and were allowed to climb up. The number of insects that climbed up to $20 \mathrm{~cm}$ mark in 1 minute was quantified. The test was presented as average of 4 repetitive experiments. ${ }^{14}$

\section{Biochemical Assays}

The fly samples for biochemical assays were prepared as follows: the adults were decapitated on ice cold PB (phosphate buffer). Heads from 100 flies were suspended in homogenizing buffer, centrifuged at $3000 \mathrm{~g}$ for 10 minutes at $4^{\circ} \mathrm{C}$ and then the supernatant was used as a sample for assaying antioxidant enzymes and oxidative markers. ${ }^{15}$ To calculate GSH, LPO and ROS levels, a standard curve of the core component was prepared. To calculate the specific activity of CAT and AchE enzymes, the following formula was employed:

Specific enzyme activity $=\Delta$ Absorbance per minute / Molar extinction coefficient $(\varepsilon) \times$ total protein content (mg).

\section{Catalase Assay}

CAT activity was determined by the method of Aebi. ${ }^{16}$ The activity of the enzyme was measured based on the decrease of absorbance at $240 \mathrm{~nm}$ which occurs as a consequence of $\mathrm{H}_{2} \mathrm{O}_{2}$ utilization. The reaction was initiated by adding $50 \mu \mathrm{L}$ of sample to $1 \mathrm{~mL}$ of reaction mixture containing 50 $\mu \mathrm{L}$ diluted $\mathrm{H} 2 \mathrm{O} 2(8.8 \mathrm{mM})$ in $900 \mu \mathrm{L}$ sodium phosphate buffer. The changes in absorbance were monitored at 240 $\mathrm{nm}$ for 3 minutes. The molar extinction coefficient of $\mathrm{H}_{2} \mathrm{O}_{2}$ was $44.1 \mathrm{mM}-1 \mathrm{~cm}-1$ and the enzyme activity was expressed as $\mu \mathrm{M}$ of $\mathrm{H}_{2} \mathrm{O}_{2}$ utilized/min/mg protein. Blank solution was a mixture of $50 \mu \mathrm{L}$ sample and $1 \mathrm{~mL}$ PB.

\section{Superoxide Dismutase Assay}

SOD activity was determined based on SOD-mediated inhibition of pyrogallol autoxidation following the method of Marklund and Marklund. ${ }^{17}$ Pyrogallol (1,2,3-benzenetriol) is known to be autoxidized quickly especially in alkaline solutions. Molecular oxygen 
carrying 2 unpaired electrons with parallel spins has a tendency for univalent reduction. SOD enzyme rapidly dismutases univalently reduced oxygen and superoxide anion radicals. Therefore, SOD enzyme can be a useful probe to study the participation of free radicals in pyrogallol autoxidation. To perform the experiment, a known volume of sample homogenate $(200 \mu \mathrm{L})$, Tris $\mathrm{HCl}$ $(2 \mathrm{~mL})$, and distilled water $(1.8 \mathrm{~mL})$ were added into the quartz cuvette. The reaction was initiated by adding 0.5 $\mathrm{mL}$ of pyrogallol solution. The inhibition of pyrogallol autoxidation was monitored at $412 \mathrm{~nm}$ for 3 minutes, and the optical density (OD) values at 1-minute intervals were measured. Pyrogallol autoxidation was calculated by monitoring the change in absorbance of a reaction mixture containing $2 \mathrm{~mL}$ Tris- $\mathrm{HCl}$ buffer, $0.5 \mathrm{~mL}$ pyrogallol $(2$ $\mathrm{mM}$ ) and $1.4 \mathrm{~mL}$ distilled water and the corresponding value was used as $100 \%$ pyrogallol autooxidation. The OD values of $100 \%$ autoxidation were subtracted from the OD values of each experimental sample, and the obtained final score indicated the inhibition of pyrogallol autooxidation. The specific activity of the enzyme was expressed as units in which 1 unit represented 50\% inhibition of pyrogallol autooxidation. Hence, the corresponding score divided by total protein content was presented in $200 \mu \mathrm{L}$ of sample and expressed as unit/mg protein. The blank solution for this assay consisted of all the reagents except pyrogallol.

\section{Acetylcholinesterase Enzyme Assay}

Acetylcholinesterase (AChE) activity was determined by the standard method of Ellman et al. ${ }^{18} \mathrm{AChE}$ proficiently hydrolyzes acetylthiocholine (ATCI), a sulfur analog of its natural substrate, acetylcholine. Following hydrolysis, the substrate analog, ATCI, produces acetate and thiocholine. Thiocholine in the presence of 5, 5'-dithiobis 2-nitrobenzoicacid (DTNB) generates 5-thio-2-nitrobenzoate anion (a yellowish substance). The yellow color obtained can be quantified using a spectrophotometer. The assay reaction mixture consisted of PB $(920 \mu \mathrm{L})$, ATCI $(25 \mu \mathrm{L})$, DTNB $(25 \mu \mathrm{L})$, and head sample $(30 \mu \mathrm{L})$ that was added into a $1 \mathrm{~mL}$ quartz cuvette. The reaction was initiated by adding acetylcholine iodide and absorbance was recorded at $412 \mathrm{~nm}$ for 3 minutes. The blank was prepared by mixing DTNB $(25 \mu \mathrm{L})$ and PB $(975 \mu \mathrm{L})$. Molar extinction coefficient value $(\varepsilon)$ for DTNB was $1.36 \times 104 \mathrm{M}-1 \mathrm{~cm}-1$ and the enzyme activity was expressed as nmoles of DTNB hydrolyzed/min/mg protein.

\section{Glutathione Assay}

GSH level was deliberated according to the method of Hissin and Hilf ${ }^{19}$ using O-phthalaldehyde (OPA). In the assay, OPA that possesses a very low fluorescence background reacts with GSH to produce strong fluorescence signals and for that reason, the GSH content can be specifically quantified. For this assay, $50 \mu \mathrm{L}$ of sample homogenate was added to $0.1 \mathrm{M}$ formic acid and spun at $5200 \mathrm{~g}$ for 10 minutes to precipitate the protein. After 30 minutes staying at room temperature to react with OPA ( $1 \mathrm{mg} / \mathrm{mL}$ in methanol), excitation and emission were at $345 \mathrm{~nm}$ and $425 \mathrm{~nm}$, respectively. The GSH level was calculated from a standard curve and expressed as $\mu \mathrm{g} \mathrm{GSH} / \mathrm{mg}$ protein. The standard curve of GSH was prepared by dissolving different concentrations (from $5 \mu \mathrm{g}$ to $40 \mu \mathrm{g}$ ) of GSH in $1 \mathrm{~mL}$ distilled water. The corresponding fluorescent signal values of each solution were documented at excitation of $345 \mathrm{~nm}$ and emission of $425 \mathrm{~nm}$. The standard plot was drawn and the line equation was used for calculation of the unknown amount of GSH in each experimental sample.

\section{Reactive Oxygen Species}

The ROS levels were calculated by means of a fluorometric method using 2',7'-Dichlorofluorescin diacetate (DCFH-DA) probe described by Black and Brandt. ${ }^{20}$ In presence of ROS, the non-fluorescent DCFHDA probe is rapidly oxidized to the highly fluorescent 2 , $7^{\prime}$-dichlorofluorescein (DCF) which can be detected via fluorometric measurements. The heads of 50 flies were homogenized in $1 \mathrm{~mL}$ ice-cold Tris- $\mathrm{HCl}$ buffer $(0.1 \mathrm{M}$; $\mathrm{pH} 7.4$ ) and centrifuged at $2000 \mathrm{~g}$ for 10 minutes at $4^{\circ} \mathrm{C}$. Afterward, $100 \mu \mathrm{L}$ of filtered supernatant was transferred to each well of the microtitre plate containing $15 \mu \mathrm{L}$ of diluted DCFH-DA and finally, the total volume was made up to $200 \mu \mathrm{L}$ by adding a Tris- $\mathrm{HCl}$ buffer. After 1 hour incubation at room temperature, the conversion of DCFH-DA to DCF was quantified at $489 \mathrm{~nm}$ excitation and $525 \mathrm{~nm}$ emission wavelengths. The fluorescent unit corresponding to each sample was recorded. The blank solution was prepared by mixing $185 \mu \mathrm{L}$ of homogenizing buffer and $15 \mu \mathrm{L}$ DCFH-DA. The concentration of DCF present in each sample was determined by the standard curve of DCFH-DA. The standard curve for DCFHDA was prepared by dissolving different concentrations (from $1.6 \mu \mathrm{g}$ to $8 \mu \mathrm{g}$ ) of the chemical in $200 \mu \mathrm{L}$ of Tris$\mathrm{HCl}$ buffer. The corresponding fluorescent units of each solution were documented at $489 \mathrm{~nm}$ excitation and 525 $\mathrm{nm}$ emission wavelengths. Using the values obtained, the standard plot was drawn and the line equation was used for calculation of ROS level in each experimental sample.

\section{Lipid Peroxidation}

Lipid peroxidation (LPO) was measured by following the method of Ohkawa et $\mathrm{al}^{21}$ using thiobarbituric acid (TBA). This assay is based on malondialdehyde (MDA) generation which is an end-product of LPO. The MDA reacts with TBA and forms a chromogenic solution. The reaction mixture contained $1.5 \mathrm{~mL}$ of $20 \%$ acetic acid ( $\mathrm{pH} 3.5$ ), $500 \mu \mathrm{L}$ of fly head homogenate, $1.5 \mathrm{~mL}$ of TBA $(0.8 \% \mathrm{w} / \mathrm{v})$ and sodium lauryl sulphate (SDS) $(8 \%$ $\mathrm{w} / \mathrm{v})$. The mixture was heated in boiling water bath for 50 minutes and adducts formed were extracted into $3 \mathrm{~mL}$ of 1-butanol. The absorbance was measured at $532 \mathrm{~nm}$ and 
quantified as malondialdehyde equivalents. Using molar extinction coefficient $(\varepsilon)$ value for tetramethoxypropane which is $15600 \mathrm{M}-1 \mathrm{~cm}-1$, the MDA contents of samples were quantified.

\section{Estimation of Total Protein Content}

Total protein concentrations in sample homogenates were quantified by following the Lowry's method. ${ }^{22}$ The principle of this method lies in the reactivity of peptide nitrogen with the copper ions under alkaline condition and succeeding in reduction of Folin-Ciocalteu reagent by copper-catalyzed oxidation of aromatic acids. In this assay, $150 \mu \mathrm{L}$ of tissue sample homogenate was added to a reaction mixture containing $0.7 \mathrm{~mL}$ alkaline cooper solution, mixed well and incubated for 10 minutes in dark at $25^{\circ} \mathrm{C}$ (room temperature). Next, $0.1 \mathrm{~mL}$ Folin-Ciocalteu reagent was added and the mixture was incubated for 20 minutes in dark at $25^{\circ} \mathrm{C}$. The absorbance was read at 750 $\mathrm{nm}$. Bovine serum albumin (BSA) was used for preparing standard curve.

\section{Preparation of the Plant Extract}

Roots of $D$. hamiltonii were collected from their natural habitat in forests of B. R. Hills, Karnataka, India. The collected roots were washed in water and then were crushed. The fleshy segment was chopped into small pieces and dried at $40^{\circ} \mathrm{C}$. Later, the dried plant roots were powdered finely by a grinder. The aqueous extract was prepared by homogenizing the root powder in warm water $\left(45^{\circ} \mathrm{C}\right)$, allowed to rest for 24 hours and filtered with Whatman No. 1 filter paper. ${ }^{23}$ The yield after lyophilization of filtrate was about $70 \mathrm{~g} / \mathrm{kg}$ of root powder.

\section{Ethanol Exposure}

The standard protocol of Maples and Rothenfluh ${ }^{23}$ was followed to measure ethanol sensitivity of the flies. For making behavioral observations, 8 flies were collected 1 day before the test and kept in a fresh media vial. To perform the test, selected flies were transferred into the vial wherein the vials plug were flooded with absolute alcohol $(0.5 \mathrm{~mL})$. The cotton plug was inserted in a way that ethanol loaded faced sides of the flies. The number of flies sedated every minute were counted and ST50 (the time taken for half of the ethanol-exposed flies to become stationary) was determined accordingly. To measure RC50 (the time taken for half of the sedated flies to be completely recovered), ethanol was added until all the flies become stationary. Afterward, all the sedated flies were transferred to the fresh media vials and the RC50 was determined. Four vials of each experimental group were maintained as a replicate. The obtained scores of 3 replicates were averaged and expressed as mean \pm standard error (SE).

Treatment of Flies With Plant Extract

In the initial step, analysis of toxicity of $D$. hamiltonii root extract was carried out. In the next step, the effective doses of $D$. hamiltonii and the time period of $D$. hamiltonii treatment were determined. Climbing ability and oxidative stress (OS) responses of flies were the parameters used for selection of $D$. hamiltonii effective doses and also effective treatment period. Preparation of $D$. hamiltonii -containing media is given in appendix section. Two-day-old flies were placed and allowed to feed on medium containing $D$. hamiltonii root aqueous extract $(0.1 \%, 0.5 \%)$. The flies were transferred to fresh food vial every 3 days.

\section{Statistical Analysis}

The data (mean \pm SE) was analyzed by one-way and twoway ANOVA followed by Duncan post-hoc comparisons using SPSS software version 19.0. The $P$ value of 0.05 was considered as the minimum level of significance and represented at 3 levels determined by asterisks in all illustrations $\left({ }^{*} P<0.05,{ }^{* *} P<0.01\right.$ and $\left.{ }^{* * *} P<0.001\right)$.

\section{Results}

Effect of Ethanol on Wild-type Flies

Excessive ethanol (EtOH) consumption induced OSmediated damage to the brain.

Acute EtOH exposure induced hyperactivity in flies as judged by the high-speed movement. On the other hand, higher doses of ethanol or long-time exposure induced the loss of postural control and finally sedation. Therefore, to check behavioral impairments induced by acute ethanol exposure, 16-day-old flies were exposed to absolute ethanol $(0.5 \mathrm{~mL})$ and the ST50 and RC50 values of their movement behavior were documented. The ST50 and RC50 values were 23 minutes and 38 minutes, respectively. As ethanol induces OS and neurotoxicity due to the reduction of endogenous antioxidant defenses, biochemical assays for CAT, SOD, and AchE enzyme activities and the levels of GSH, ROS and LPO in 16-dayold flies after ethanol exposure were carried out. The results obtained are represented in Figure 1, the perusal of which reveals that ethanol induced elevation in the activity of CAT and SOD enzymes.

Further scrutiny of the figure also shows significant depletion of GSH level in ethanol-exposed flies (12.6 \pm 0.6 $\mu \mathrm{g} \mathrm{GSH} / \mathrm{mg}$ protein) compared to control flies (17.5 \pm 1.4 $\mu \mathrm{g}$ GSH/mg protein). The LPO and ROS levels were found to be notably higher in ethanol-exposed flies. The flies exposed to ethanol showed $9.8 \pm 0.19 \mathrm{nM} \mathrm{MDA} / \mathrm{mg}$ protein and $950 \pm 39.6 \mu \mathrm{M} \mathrm{DCF} / \mathrm{mg}$ protein for LPO and ROS levels, respectively. The AChE activity was found to be $110 \pm 4.2 \mu \mathrm{M} \mathrm{DTNB} / \mathrm{min} / \mathrm{mg}$ protein in ethanolexposed flies; while the enzyme showed the activity level of $75 \pm 2.9 \mu \mathrm{M} \mathrm{DTNB} / \mathrm{min} / \mathrm{mg}$ protein in the control flies. Statistical analysis of the data revealed that ethanol induced significant alterations in all the biochemical assays $(P<0.001, \mathrm{n}=4)$. Duncan test also revealed that this level of alterations in the enzyme activities and OS 

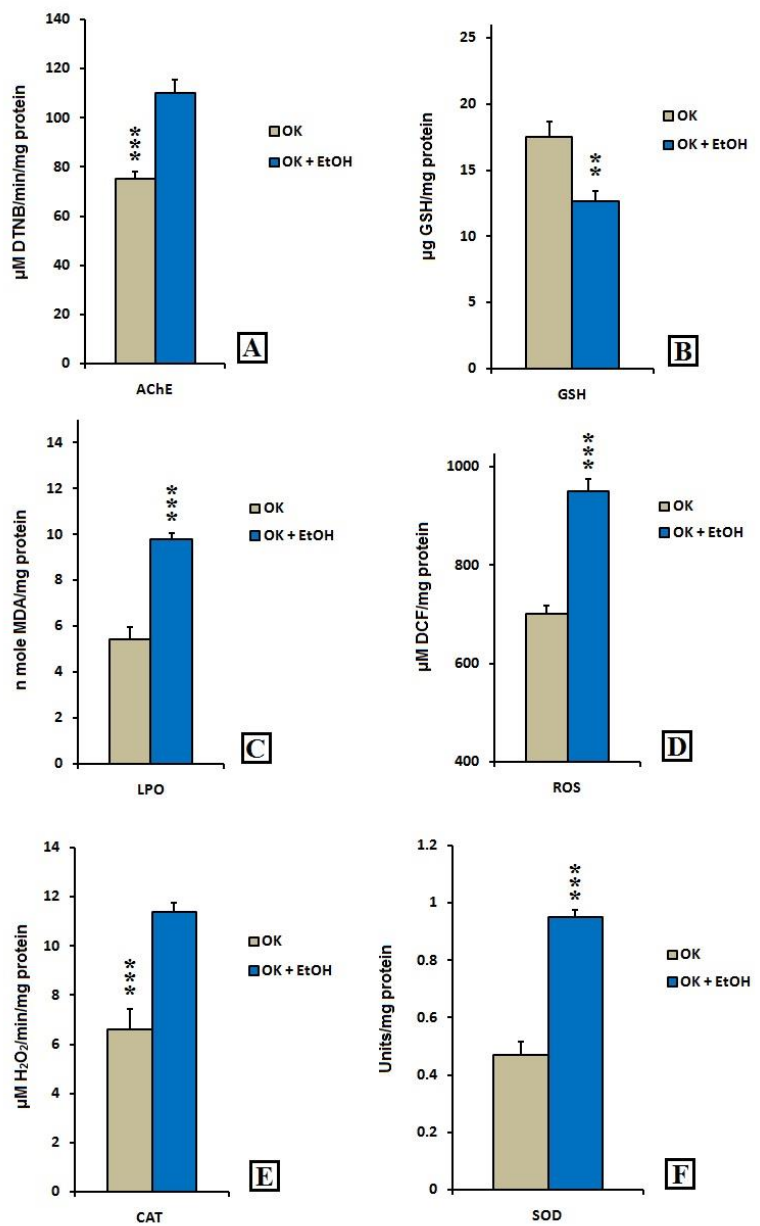

Figure 1. Biochemical Analysis of Antioxidant Enzymes, Oxidative Markers and AchE in Wild-type D. melanogaster (Oregon K) Exposed to Ethanol. (A) AchE activity, (B) GSH level, (C) LPO level, (D) ROS level, (E) Catalase activity, (F) SOD activity.

markers after ethanol exposure was significant $(P=$ $0.0009, \mathrm{n}=4)$.

\section{Decalepis hamiltonii Treatment}

The main concern of this study was to investigate the antioxidant and neuroprotective effect of $D$. hamiltonii aqueous extract as potent antioxidant against OS induced by ethanol in wild-type (Oregon K) flies. In the initial step, analysis of toxicity of $D$. hamiltonii aqueous extract showed no mortality at any dose. In the next step, the effective doses of $D$. hamiltonii and the time period of D. hamiltonii treatment were evaluated. Climbing ability and OS responses of flies were the parameters used for selection of $D$. hamiltonii effective doses and also effective treatment period. Two concentrations of $D$. hamiltonii $(0.1 \%, 0.5 \%)$ were selected based on the initial studies (data are not shown). Moreover, 14 days of $D$. hamiltonii feeding was chosen as the effective treatment period.

The ethanol-induced locomotor deficits of 16-day-old flies pre-fed with $D$. hamiltonii for 14 days were measured by exposure to $0.5 \mathrm{~mL}$ absolute ethanol and determination of ST50 and RC50 values.
The results of ST50 are shown in Figure 2. The RC50 values of flies pre-fed with $D$. hamiltonii are shown in Figure 3. A scrutiny of these figures reveals that pre-feeding of flies with $D$. hamiltonii increased the acute ethanol ST50 and decreased the RC50 value of flies compared to unfed ones $(P=0.0038, \mathrm{n}=4)$.

To further substantiate the neuroprotective effect of $D$. hamiltonii, biochemical assays were made on the same flies (16-day-old flies pre-fed with $D$. hamiltonii for 14 days and exposed to $0.5 \mathrm{~mL}$ absolute ethanol). The results obtained are compiled in Table 1 and Table 2.

A careful analysis of these results showed that ethanol exposure led to the obvious exhaustion of GSH in flies, and $D$. hamiltonii pre-feeding suppressed the depletion. Flies exposed to EtOH had elevated LPO compared to the untreated flies. Pre-feeding the flies with $D$. hamiltonii extract considerably decreased the LPO near to the basal levels. Ethanol exposure increased activity of SOD, which was restored in $D$. hamiltonii pre-fed flies to the enzyme

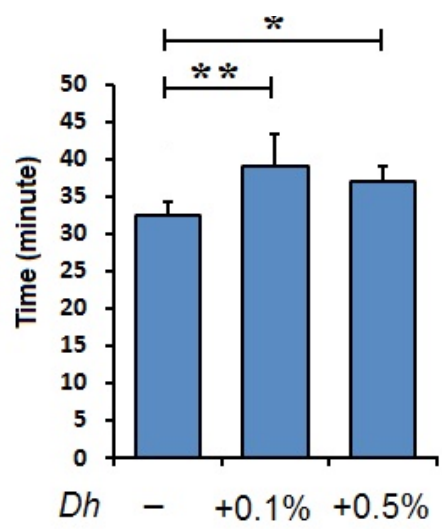

Figure 2. Ameliorative Effect of $D$. hamiltonii on Locomotion Behavioral Impairments Induced by Ethanol. Ethanol-induced sedation measured by ST50 in control flies and D. hamiltonii treated ones. ST50 value significantly increased in $0.1 \% D$. hamiltonii - $(P=0.0062)$ and $0.5 \%$ $D$. hamiltonii - $(P=0.0047)$ treated groups in comparison with control untreated flies. Abbreviation: $D h, D$. hamiltonii.

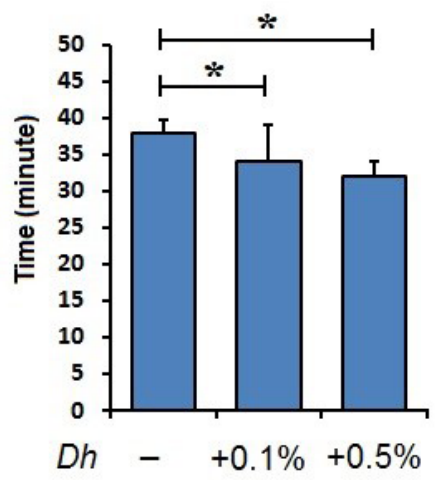

Figure 3. RC50 Value of Flies Exposed to Ethanol and Neuroprotective Effects of $D$. hamiltonii. D. hamiltonii treatment significantly decreased RC50 of flies $(P=0.0049$ for $0.1 \%$ D. hamiltonii and controls, and $P=$ 0.0038 for $0.5 \%$ D. hamiltonii and controls). 
Table 1. Mean \pm SE of Endogenous Antioxidant Enzyme Activity, Oxidative Markers and AchE in Wild-type Drosophila melanogaster (Oregon K) Flies Exposed to Ethanol Showing Antioxidant Potential of Decalepis hamiltonii treatment

\begin{tabular}{|c|c|c|c|c|c|c|c|}
\hline Genotype & Diet & AchE & CAT & SOD & GSH & LPO & ROS \\
\hline \multirow{4}{*}{$\begin{array}{l}\text { Wild-type } \\
\text { (Oregon K) }\end{array}$} & Control & $75.0 \pm 7.3$ & $6.6 \pm 0.26$ & $0.47 \pm 0.04$ & $17.5 \pm 0.3$ & $5.4 \pm 0.65$ & $700 \pm 85.3$ \\
\hline & $100 \% \mathrm{EtOH}$ & $110 \pm 6.1$ & $11.4 \pm 0.43$ & $0.95 \pm 0.04$ & $12.6 \pm 0.4$ & $9.8 \pm 0.21$ & $950 \pm 14.6$ \\
\hline & $\mathrm{EtOH}+0.1 \%$ Decalepis hamiltonii & $85.0 \pm 2.3$ & $7.8 \pm 0.86$ & $0.56 \pm 0.08$ & $16.4 \pm 0.1$ & $6.6 \pm 0.37$ & $800 \pm 23.2$ \\
\hline & $P$ & $<0.01$ & $<0.001$ & $<0.01$ & $<0.05$ & $<0.001$ & $<0.01$ \\
\hline
\end{tabular}

ROS, Reactive oxygen species levels ( $\mu \mathrm{M}$ DCF/mg protein); AchE, Acethylcholinesterase; CAT, Catalase specific activity ( $\mu \mathrm{M} \mathrm{H} 2 \mathrm{O} 2 / \mathrm{min} / \mathrm{mg}$ protein); $\mathrm{SOD}$, Superoxide dismutase specific activity (units/mg protein); GSH = Glutathione levels ( $\mu$ g GSH/mg protein); LPO = Lipid peroxidation levels (nM $\mathrm{MDA} / \mathrm{mg}$ protein).

Table 2. Mean \pm SE of Endogenous Antioxidant Enzyme Activity, Oxidative Markers and AchE in Wild-type Drosophila melanogaster (Oregon K) Flies Exposed to Ethanol Showing Antioxidant Potential of DHA-I Treatment

\begin{tabular}{|c|c|c|c|c|c|c|c|}
\hline Genotype & Diet & AchE & CAT & SOD & GSH & LPO & ROS \\
\hline \multirow{4}{*}{$\begin{array}{l}\text { Wild-type } \\
\text { (Oregon K) }\end{array}$} & Control & $70 \pm 4.1$ & $7 \pm 0.27$ & $0.33 \pm 0.02$ & $16 \pm 0.36$ & $5 \pm 0.08$ & $620 \pm 29.2$ \\
\hline & $\mathrm{EtOH}$ & $106 \pm 3.3$ & $12.2 \pm 0.4$ & $0.84 \pm 0.06$ & $11.4 \pm 0.07$ & $8.7 \pm 0.05$ & $880 \pm 21.4$ \\
\hline & $\mathrm{EtOH}+0.5 \%$ Decalepis hamiltonii & $80.0 \pm 4.7$ & $7.2 \pm 0.62$ & $0.51 \pm 0.02$ & $17.0 \pm 0.9$ & $6.2 \pm 0.84$ & $770 \pm 48.6$ \\
\hline & $P$ & $<0.05$ & $<0.01$ & $<0.01$ & $<0.01$ & $<0.05$ & $<0.01$ \\
\hline
\end{tabular}

ROS, Reactive oxygen species levels ( $\mu \mathrm{M}$ DCF/mg protein); AchE, Acethylcholinesterase; CAT, Catalase specific activity ( $\mu \mathrm{M} \mathrm{H} 2 \mathrm{O} 2 / \mathrm{min} / \mathrm{mg}$ protein); SOD, Superoxide dismutase specific activity (units/mg protein); GSH = Glutathione levels ( $\mu \mathrm{g}$ GSH/mg protein); LPO = Lipid peroxidation levels (nM $\mathrm{MDA} / \mathrm{mg}$ protein).

activity level observed in control flies. Similarly, exposure to EtOH also boosted CAT activity whilst $D$. hamiltonii treatment inhibited CAT enzyme activity similar to the flies without ethanol exposure. Flies exposed to ethanol showed an elevation in the AChE activity similar to $D$. hamiltonii-unfed flies. D. hamiltonii pre-feeding restored the activity of AChE to the levels observed in control flies. Statistical analysis of the results followed by Duncan post hoc comparison revealed that $D$. hamiltonii significantly ameliorated the neurotoxicity induced by ethanol in wildtype flies $(P=0.0087, \mathrm{n}=4)$.

\section{Discussion}

For fruit fly, alcohol (EtOH) serves as an environmental indication to locate decomposing fruits. The remarkable association between Drosophila and ethanol makes it a gorgeous model organism to elucidate the mechanisms underlying ethanol-induced behavioral responses. Numerous kinds of behavioral responses to ethanol are conserved from flies to mammals. ${ }^{24}$ Hyperactivity and sedation are of common responses to acute alcohol exposure in both human and fruit fly.

The results of the present study revealed that ethanol exposure caused significant behavioral impairments, which were investigated by measuring ST50 and RC50 values. The findings of the present study represented significant elevation in the levels of ROS and LPO and marked depletion in GSH level in the flies exposed to ethanol. Moreover, flies exposed to ethanol showed increased activities of CAT, SOD, and AchE. These results imply the role of ethanol in inducing OS in flies as was evident by elevated levels of oxidative stress markers and significant alterations in the activity of antioxidant enzymes.

Excessive ethanol consumption induces OS and leads to damages to the brain. Neurotoxicity of ethanol goes together with production of ROS and a decrease in endogenous cellular antioxidant defense syetem. ${ }^{3,25}$ Acute ethanol exposure causes elevation of membrane LPO in the brain which can be suppressed by antioxidant agents. ${ }^{26}$ Acute EtOH intake also results in depression of glutathione and protein carbonyl formation which can be used as common markers of OS in the brain. ${ }^{27,28}$ As one of the major metabolites in fruit fermentation is ethanol, fruit flies repeatedly encounter ethanol in their natural environment. Drosophila is a suitable model organism to explore ethanol neurotoxicity as the enzymatic mechanism of ethanol metabolization..$^{29}$ Many types of behavioral responses to EtOH including hyperactivity, sedation, alcohol tolerance, and alcohol preference are well known in fruit flies and mammals. It is evident that acute EtOH exposure induces hyperactivity in flies as evaluated by the higher speed of walking. Furthermore, flies display alcohol tolerance following repetitive exposure. ${ }^{30}$ Many of dopaminergic neurons are concerned in ethanol-related mutilations in mammals as well as in Drosophila. ${ }^{31}$

As ethanol induces OS in the brain which leads to neurobehavioral impairments, natural antioxidants are helpful to ameliorate OS and therefore, can serve as defensive therapeutic agents for the treatment of neurodegenerative diseases. The roots of $D$. hamiltonii are used as general vitalizer in folk medicine in southern India. The root extract of $D$. hamiltonii is a cocktail of novel natural antioxidants. Several of them that have 
been isolated and characterized are DHA-I (4-hydroxy isophthalic acid), DHA-II (14-aminotetradecanoic acid), DHA-III (4-(1-hydroxy-1methylethyl)-1-methyl-1, 2-cyclohexane diol), DHA-IV (2-hydroxy methyl-3methoxy benzaldehyde), DHA-V (2,4,8-trihydroxy bicyclo[3.2.1] octan-3-one), and ellagic acid which have been shown to possess free radical scavenging activity in vitro. ${ }^{11,12}$

It is obvious from the present study that wild-type flies treated with $D$. hamiltonii aqueous extract exposed to ethanol demonstrated a lower frequency of mortality and marked reduction of behavioral impairments. The neuroprotective effect of $D$. hamiltonii was comparable to that of quercetin, zedoariaerhizoma, curcumin, and Sanguisorba officinalis with regard to negative geotaxis assay. ${ }^{32}$ The ethanol-exposed flies showed remarkable induction of OS as shown by elevation of LPO and ROS, depletion of GSH, and altered antioxidant enzyme profile of flies. D. hamiltonii caused suppression of OS induced by ethanol as was evident by oxidative markers. GSH level in the flies treated with $D$. hamiltonii was considerably reduced, suggesting that ameliorative effect of $D$. hamiltonii can be credited to radical scavenging along with increased GSH synthesis. The activity of CAT and SOD enzymes were induced by ethanol in flies, which were reversed in D. hamiltonii-treated ones. These results indicated that $D$. hamiltonii modulated antioxidant pathways in flies by restoring their redox status. In this study, ethanol also caused an elevation in the activity of AchE and it can be considered as a strong evidence for defective dopaminergic neurotransmission. Exposure to D. hamiltonii extract decreased AchE activity and then protected Drosophila against the neurotoxic effect of ethanol. Therefore, neuroprotective potential of $D$. hamiltonii extract can be attributed to their ability to abrogate OS induced by ethanol in Drosophila brain. Since the brain is rich in oxidizable substrates and is poor in antioxidant defenses, it is susceptible to OS. Therefore, the neuroprotective efficiency of $D$. hamiltonii is evident by its ability to attenuate OS induced by ethanol, to restore AchE activity in the fly brain, to significantly improve the locomotion performance, and to raise survival rate after treatment with $D$. hamiltonii extract. To know the biochemical processes involved in behavioral impairments in Drosophila can be beneficial to explore new therapies enhancing the antioxidant defenses. The present study was the first report on neuroprotective efficiency of $D$. hamiltonii against OS induced by ethanol in Drosophila model organism.

OS has been implicated in the neurological dysfunctions of neurological diseases like $\mathrm{PD}, \mathrm{AD}$ and Amytropic lateral sclerosis (ALS). ${ }^{33}$ In the same scenario, OS has been shown to be a major factor in the onset of PD symptoms, ${ }^{34}$ while enhancement of ROS level accompanies $\alpha$-synuclein aggregation and consequent degeneration of dopaminergic neurons. ${ }^{35}$ Intracellular overexpression of a-synuclein gene generates excessive ROS resulting in some damages to the cell membrane, mitochondrial dysfunction, and decline in the GSH level, all of which make the brain defenseless against oxidative damage. ${ }^{36}$ Recent therapeutic managements of PD have been based on the exploit of natural antioxidants to diminish OS, besides the use of the therapeutic approaches to increase the activity of dopaminergic neurons to inhibit the cholinergic effects on the striatum. ${ }^{37}$ For that reason, a powerful neuroprotective compound can prevent or postpone the onset of age-associated devastating conditions of PD patients. ${ }^{38,39}$ Dietetic supplementation of antioxidant-rich plant in humans and animals have illustrated outstanding improvements in neuronal functions probably by the protection of susceptible neurons, raising functions of accessible neurons or promoting regeneration of neurons. ${ }^{40}$ Consequently, natural antioxidants are capable of being the choice to modulate the OS; therefore, they are preserved as potential preventative therapeutic agents for the treatment of neurodegenerative conditions. ${ }^{41,42}$ Natural antioxidants have been reported to operate as molecular inhibitors of a-synuclein misfolding and aggregation. Therefore, these agents could be achievable protective factors to decelerate the progression of PD. Current studies illustrate that antioxidants induce remodeling effects on $\alpha$-synuclein aggregates to renovate them to nontoxic species $^{43}$. The neuroprotective efficiency of antioxidant supplementation might be valuable in Drosophila model when applied in an earlier age. ${ }^{44,45}$

\section{Conclusion}

Our biochemical investigations showed a marked increase in the activity of CAT and SOD enzymes, remarkable reduction in GSH level and a significant increase in the levels of LPO and ROS and activity of AchE in wild-type flies exposed to ethanol. It is evident from the present study that the neuroprotective effect of $D$. hamiltonii against neurotoxicity induced by ethanol in wild-type flies was associated with their potential to modulate changes in the levels of oxidative stress markers and antioxidant defense system. Moreover, D. hamiltonii attenuated behavioral impairments induced by ethanol in wild-type flies.

\section{Ethical Approval \\ Not applied.}

\section{Competing Interests}

The author declares no competing interests.

\section{Acknowledgments}

The author thanks the Chairman at Department of Studies in Zoology, University of Mysore, Mysore, and the Director at Institution of Excellence, University of Mysore for the facilities. The author also thanks the Chairperson at Department of Biology, University of Sistan and 
Baluchestan, Zahedan for the supports. The author thanks Dr. Mohammad Haddadi, Department of Biology, University of Zabol, Dr. Mohan J, Mr. Rohith BN, Mrs. Niveditha, and Mrs Deepashree, Department of Studies in Zoology, University of Mysore, Mysore, for their help.

\section{References}

1. Ikonomidou C, Bittigau P, Ishimaru MJ, et al. Ethanolinduced apoptotic neurodegeneration and fetal alcohol syndrome. Science. 2000;287(5455):1056-1060. doi:10.1126/science.287.5455.1056

2. Baker RC, Kramer RE. Cytotoxicity of short-chain alcohols. Annu Rev Pharmacol Toxicol. 1999;39:127-150. doi:10.1146/annurev.pharmtox.39.1.127

3. Das SK, Vasudevan DM. Alcohol-induced oxidative stress. Life Sci. 2007;81(3):177-187. doi:10.1016/j.lfs.2007.05.005

4. Ames BN. Endogenous oxidative DNA damage, aging, and cancer. Free Radic Res Commun. 1989;7(3-6):121-128. doi:10.3109/10715768909087933

5. Tsang AH, Chung KK. Oxidative and nitrosative stress in Parkinson's disease. Biochim Biophys Acta. 2009;1792(7):643-650. doi:10.1016/j.bbadis.2008.12.006

6. Swerdlow RH, Parks JK, Miller SW, et al. Origin and functional consequences of the complex I defect in Parkinson's disease. Ann Neurol. 1996;40(4):663-671. doi:10.1002/ana.410400417

7. Zhang Y, Marcillat O, Giulivi C, Ernster L, Davies KJ. The oxidative inactivation of mitochondrial electron transport chain components and ATPase. J Biol Chem. 1990;265(27):16330-16336

8. Gilgun-Sherki Y, Melamed E, Offen D. Oxidative stress induced-neurodegenerative diseases: the need for antioxidants that penetrate the blood brain barrier. Neuropharmacology. 2001;40(8):959-975. doi:10.1016/ s0028-3908(01)00019-3

9. Nayar RC, Shetty JKP, Mary Z, Yoganarasimhan SN. Pharmacognostical studies on the root of Decalepis hamiltonii Wt. and Arn., and comparison with Hemidesmus indicus (L.) R. Br. Paper presented at: Proceedings of the Indian Academy of Sciences-Section B1978.

10. Chandrasekhara Reddy M, Sri Rama Murthy K. A Review on Decalepis hamiltonii Wight \& Arn. J Med Plant Res. 2013;7(41):3014-3029. doi:10.5897/JMPR2013.5099

11. Srivastava A, Harish R, Shivanandappa T. Novel antioxidant compounds from the aqueous extract of the roots of Decalepis hamiltonii (Wight and Arn.) and their inhibitory effect on low-density lipoprotein oxidation. J Agric Food Chem. 2006;54(3):790-795. doi:10.1021/jf052433x

12. Srivastava A, Jagan Mohan Rao L, Shivanandappa T. A novel cytoprotective antioxidant: 4-Hydroxyisophthalic acid. Food Chem. 2012;132(4):1959-1965. doi:10.1016/j. foodchem.2011.12.032

13. Srivastava A, Shivanandappa T. Neuroprotective effect of Decalepis hamiltonii roots against ethanol-induced oxidative stress. Food Chem. 2010;119(2):626-629. doi:10.1016/j.foodchem.2009.07.003

14. Feany MB, Bender WW. A Drosophila model of Parkinson's disease. Nature. 2000;404(6776):394-398. doi: $10.1038 / 35006074$

15. Jahromi SR, Haddadi M, Shivanandappa T, Ramesh SR.
Attenuation of neuromotor deficits by natural antioxidants of Decalepis hamiltonii in transgenic Drosophila model of Parkinson's disease. Neuroscience. 2015;293:136-150. doi:10.1016/j.neuroscience.2015.02.048

16. Aebi H. [13] Catalase in vitro. Methods Enzymol. 1984;105:121-126. doi:10.1016/S0076-6879(84)05016-3

17. Marklund S, Marklund G. Involvement of the superoxide anion radical in the autoxidation of pyrogallol and a convenient assay for superoxide dismutase. Eur J Biochem. 1974;47(3):469-474. doi:10.1111/j.1432-1033.1974. tb03714.x

18. Ellman GL, Courtney KD, Andres V Jr, Feather-Stone RM. A new and rapid colorimetric determination of acetylcholinesterase activity. Biochem Pharmacol. 1961;7(2):88-95. doi:10.1016/0006-2952(61)90145-9

19. Hissin PJ, Hilf R. A fluorometric method for determination of oxidized and reduced glutathione in tissues. Anal Biochem. 1976;74(1):214-226. doi:10.1016/00032697(76) $90326-2$

20. Black MJ, Brandt RB. Spectrofluorometric analysis of hydrogen peroxide. Anal Biochem. 1974;58(1):246-254. doi:10.1016/0003-2697(74)90464-3

21. Ohkawa H, Ohishi N, Yagi K. Assay for lipid peroxides in animal tissues by thiobarbituric acid reaction. Anal Biochem. 1979;95(2):351-358. doi:10.1016/00032697(79)90738-3

22. Lowry OH, Rosebrough NJ, Farr AL, Randall RJ. Protein measurement with the Folin phenol reagent. J Biol Chem. 1951;193(1):265-275.

23. Maples T, Rothenfluh A. A simple way to measure ethanol sensitivity in flies. J Vis Exp. 2011(48). doi:10.3791/2541

24. Morean ME, Corbin WR. Subjective response to alcohol: a critical review of the literature. Alcohol Clin Exp Res. 2010;34(3):385-395. doi:10.1111/j.1530-0277.2009.01103.x

25. Lieber CS. Metabolism of Alcohol. Clin Liver Dis. 2005;9(1):1-35. doi:10.1016/j.cld.2004.10.005

26. Dey A, Cederbaum AI. Alcohol and oxidative liver injury. Hepatology. 2006;43(2 Suppl 1):S63-74. doi:10.1002/ hep. 20957

27. Altomare E, Grattagliano I, Vendemiale G, Palmieri V, Palasciano G. Acute ethanol administration induces oxidative changes in rat pancreatic tissue. Gut. 1996;38(5):742-746. doi:10.1136/gut.38.5.742

28. Calabrese V, Testa G, Ravagna A, Bates TE, Stella AM. HSP70 induction in the brain following ethanol administration in the rat: regulation by glutathione redox state. Biochem Biophys Res Commun. 2000;269(2):397400. doi:10.1006/bbrc.2000.2311

29. Guarnieri DJ, Heberlein U. Drosophila melanogaster, a genetic model system for alcohol research. Int Rev Neurobiol. 2003;54:199-228.

30. Kaun KR, Devineni AV, Heberlein U. Drosophila melanogaster as a model to study drug addiction. Hum Genet. 2012;131(6):959-975. doi:10.1007/s00439-012$1146-6$

31. King I, Tsai LT, Pflanz R, et al. Drosophila tao controls mushroom body development and ethanol-stimulated behavior through par-1. J Neurosci. 2011;31(3):1139-1148. doi:10.1523/jneurosci.4416-10.2011

32. Park JH, Jung JW, Ahn YJ, Kwon HW. Neuroprotective properties of phytochemicals against paraquat-induced 
oxidative stress and neurotoxicity in Drosophila melanogaster. Pestic Biochem Physiol. 2012;104(2):118125. doi:10.1016/j.pestbp.2012.07.006

33. Lin MT, Beal MF. Mitochondrial dysfunction and oxidative stress in neurodegenerative diseases. Nature. 2006;443(7113):787-795. doi:10.1038/nature05292

34. Jenner P, Olanow CW. The pathogenesis of cell death in Parkinson's disease. Neurology. 2006;66(10 Suppl 4):S2436. doi:10.1212/WNL.66.10_suppl_4.S24

35. Quilty MC, King AE, Gai WP, et al. Alpha-synuclein is upregulated in neurones in response to chronic oxidative stress and is associated with neuroprotection. Exp Neurol. 2006;199(2):249-256. doi:10.1016/j.expneurol.2005.10.018

36. Mancuso C, Scapagini G, Curro D, et al. Mitochondrial dysfunction, free radical generation and cellular stress response in neurodegenerative disorders. Front Biosci. 2007;12:1107-1123. doi:10.2741/2130

37. Ono K, Yamada M. Antioxidant compounds have potent anti-fibrillogenic and fibril-destabilizing effects for alphasynuclein fibrils in vitro. J Neurochem. 2006;97(1):105115. doi:10.1111/j.1471-4159.2006.03707.x

38. Uttara B, Singh AV, Zamboni P, Mahajan RT. Oxidative stress and neurodegenerative diseases: a review of upstream and downstream antioxidant therapeutic options. Curr Neuropharmacol. 2009;7(1):65-74. doi:10.2174/157015909787602823

39. Yacoubian TA, Standaert DG. Targets for neuroprotection in Parkinson's disease. Biochim Biophys Acta.
2009;1792(7):676-687. doi:10.1016/j.bbadis.2008.09.009

40. Vauzour D, Vafeiadou K, Rodriguez-Mateos A, Rendeiro C, Spencer JP. The neuroprotective potential of flavonoids: a multiplicity of effects. Genes Nutr. 2008;3(3-4):115-126. doi:10.1007/s12263-008-0091-4

41. Lu JM, Nurko J, Weakley SM, et al. Molecular mechanisms and clinical applications of nordihydroguaiaretic acid (NDGA) and its derivatives: an update. Med Sci Monit. 2010;16(5):Ra93-100.

42. Pal R, Miranda M, Narayan M. Nitrosative stress-induced Parkinsonian Lewy-like aggregates prevented through polyphenolic phytochemical analog intervention. Biochem Biophys Res Commun. 2011;404(1):324-329. doi:10.1016/j. bbrc.2010.11.117

43. Bieschke J, Russ J, Friedrich RP, et al. EGCG remodels mature alpha-synuclein and amyloid-beta fibrils and reduces cellular toxicity. Proc Natl Acad Sci U S A. 2010;107(17):7710-7715. doi:10.1073/pnas.0910723107

44. Faust K, Gehrke S, Yang Y, Yang L, Beal MF, Lu B. Neuroprotective effects of compounds with antioxidant and anti-inflammatory properties in a Drosophila model of Parkinson's disease. BMC Neurosci. 2009;10:109. doi:10.1186/1471-2202-10-109

45. Lavara-Culebras E, Paricio N. Drosophila DJ-1 mutants are sensitive to oxidative stress and show reduced lifespan and motor deficits. Gene. 2007;400(1-2):158-165. doi:10.1016/j. gene.2007.06.013 